\title{
CAPÍTULO 30: ESTUDO DA CINÉTICA DE SECAGEM E CARACTERIZAÇÃO FÍSICO-QUÍMICA DA POLPA DE PITANGA (Eugenia uniflora)
}

\section{CHAPTER 30: STUDY OF DRYING KINETICS AND PHYSICAL AND CHIMICAL CHACACTERIZATION OF PITANGA PULP (Eugenia uniflora)}

\author{
Claudinéia Aparecida Queli Geraldi ${ }^{1}$; Maria Fernanda Alves Faria Andrade ${ }^{2}$; Fabiano de \\ Paula Pereira Machado ${ }^{3}$ Raquel Aparecida Loss ${ }^{4}$; Sumaya Ferreira Guedes ${ }^{5}$
}

\section{Resumo}

O Brasil apresenta clima diversificado, o que permite a produção de diversos tipos de frutas, destacando-se como produtor frutícola mundial, porém, desperdícios ocorrem devido ao uso de técnicas inadequadas de colheita, pós-colheita, armazenamento, transporte e além da sazonalidade. Portanto, o presente estudo objetivou a realização da cinética de secagem em camada de espuma em diferentes temperaturas e análise das propriedades físico-químicas da polpa de pitanga. Os modelos matemáticos utilizados foram de Midilli e Kucuk e Page, porém o que apresentou melhor ajuste foi o de Page. Em relação às características físico-químicas, a polpa in natura apresentou valor de $\mathrm{pH}$ de 3,12 e para as polpa seca de 3,12 e 3,13. O teor de cinzas para a polpa in natura foi de 0,27 e para as polpas secas variou de 2,11 a $2,16 \%$ e o teor de vitamina $\mathrm{C}$ concentrou com a secagem, destacando-se a secagem da polpa a $60{ }^{\circ} \mathrm{C}$ que apresentou $74,37 \mathrm{mg} / 100 \mathrm{~g}$ de vitamina C. A acidez total titulável para a polpa in natura foi de 3,014 e para as polpas secas variou de 15,7 a $15,88 \mathrm{~g}$ de ácido/100g. Os valores de umidade reduziram com a elevação da temperatura de secagem

Palavras-Chaves: Frutas, conservação de alimentos, modelagem matemática.

\begin{abstract}
Brazil has a diverse climate, which allows the production of several types of fruit, standing out as a world fruit producer, however, waste occurs due to the use of inappropriate harvesting, post-harvesting, storage, transport and seasonality techniques. Therefore, the present study aimed to perform the kinetics of drying in foam layer at different temperatures and analysis of the physicochemical properties of pitanga pulp. The mathematical models used were from Midilli and Kucuk and Page, but the best adjustment was Page. In relation to the physicalchemical characteristics, the pulp in natura $\mathrm{pH}$ value of 3.12 and for dry pulp 3.12 and 3.13. The ash content for the flesh pulp was 0.27 and for the dry pulp it varied from 2.11 to $2.16 \%$ and the vitamin $\mathrm{C}$ content concentrated with drying, with the pulp drying at $60{ }^{\circ} \mathrm{C}$ standing vitamin C $74.37 \mathrm{mg} / 100 \mathrm{~g}$ vitamin $\mathrm{C}$. The titratable total acidity for the fresh pulp was 3.014 and for the dry pulp it varied from 15.7 to $15.88 \mathrm{~g}$ of acid/100g. The humidity values decreased with increasing druing temperature.
\end{abstract}

Keywords: Fruit, food conservation, mathematical modeling.

\footnotetext{
${ }^{1}$ Agronomia, Universidade do Estado de Mato Grosso, claudigeraldi@onda.com.br

${ }^{2}$ Engenharia de Alimentos, Universidade do Estado de Mato Grosso, fernaandafarias@ gmail.com

${ }^{3}$ Engenharia de Alimentos, Universidade do Estado de Mato Grosso, fmachado@ unemat.br

${ }^{4}$ Engenharia de Alimentos, Universidade do Estado de Mato Grosso, raquelloss@ unemat.br

${ }^{5}$ Doutora, Universidade do Estado de Mato Grosso, su_sumaya@yahoo.com.br
} 


\section{Introdução}

O Brasil é um país que se destaca como um dos maiores produtores frutícolas mundiais. Isso está diretamente ligado ao fato de ser um país continental com climas variados, possibilitando uma imensa capacidade de produzir variados tipos de frutas, desde as de clima tropical até as que necessitam de clima temperado para seu cultivo. No entanto, estimativas apontam para desperdícios na produção, devido a técnicas inadequadas de colheita, póscolheita, armazenamento, transporte e sazonalidade (DANTAS, 2010).

Eugenia uniflora comumente conhecida como pitanga, possui elevado valor nutricional e atributos sensoriais de grande aceitação pelo consumidor. Possui proteínas, lipídeos e uma quantidade significante de carboidratos. Com relação ao potencial funcional é rica em compostos fenólicos, flavonoides e possui atividade antioxidante (SILVA, 2016; VOLPATO et al, 2015).

O nome pitanga é oriundo da palavra indígena tupi pyrang, a qual tem o significado de vermelho profundo, essa fruta possui outras denominações em diferentes regiões do Brasil e outros países, como cereja pitanga, pitango, cereja brasileira, ibitanga, cereja do Suriname cerejeira de Cayenne (BRASIL, 2015; EMBRAPA, 2015).

A pitanga é uma baga (fruto pequeno, carnoso e com semente no seu interior) que tem em média $23 \%$ de caroço e $77 \%$ de polpa, apresenta de 1,5 a 3 centímetros de diâme tro e é fixada na pitangueira através de um pedúnculo com comprimento de aproximadamente dois a três centímetros (BOURSCHEID et al., 2011; EMBRAPA, 2015; SILVA, 2016). A Figura 1, reforça a aparência atrativa de pitangas maduras coletadas na região do Centro-Oeste do Brasil.

Figura 1. Pitangas maduras da região Centro-Oeste do Brasil.

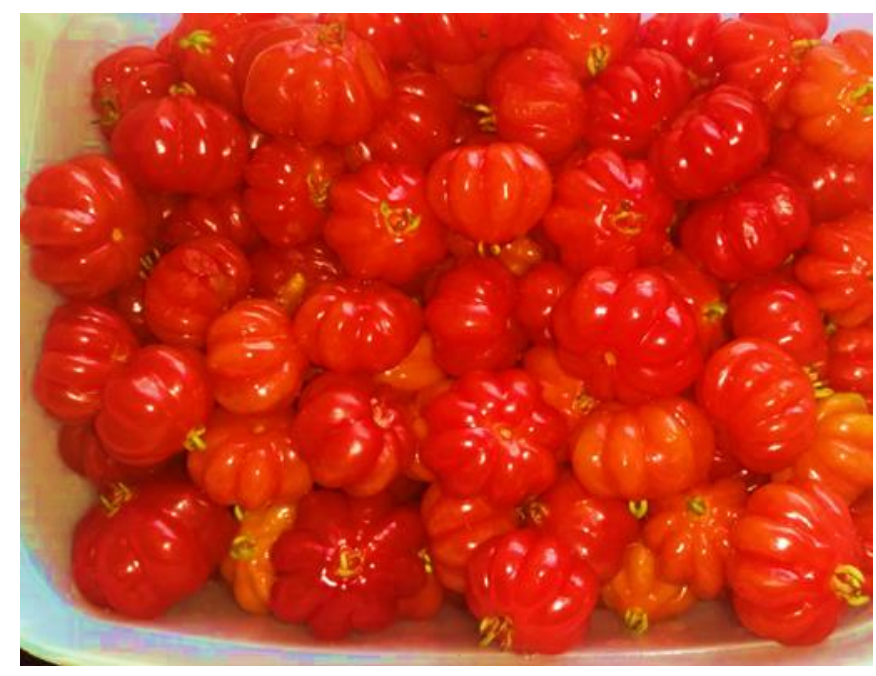

Fonte: Própria (2019). 
A pitanga é caracterizada pelo seu sabor, o qual possui equilíbrio entre ácido e doce, aroma agradável, bela aparência, possuindo uma coloração alaranjada, vermelha ou roxa, além dos aspectos nutricionais que são desejáveis, visto que a polpa dessa fruta é rica em antocianinas, flavonoides, carotenoides e antioxidantes, também apresenta um alto teor de vitaminas, sendo a vitamina A, complexo B e C, além disso os sais minerais também estão presentes na pitanga, entre eles encontram-se o ferro, fósforo e cálcio (BOURSCHEID et al., 2011; LIMA et al., 2017; SILVA, 2016; VOLPATO et al, 2015).

As substâncias antioxidantes são capazes de absorver os radicas livres existentes nos organismos, impedindo danos realizados pela oxidação, desta forma têm a capacidade de retardar o envelhecimento precoce, além disso é possível prevenir doenças crônicas, cardiovasculares, catarata e alguns tipos de câncer (EMBRAPA, 2015; SILVA, 2010). Para a ingestão desses compostos recomenda-se o consumo de frutas e vegetais, em especial de coloração avermelhada, lilás, azul, violeta, os quais possuem antocianinas, e aquelas de coloração amarelo pálido e marfim, cujos têm flavonoides em sua composição (PEREIRA, 2012).

Entretanto, devido à perecibilidade, não é possível transportá-la in natura para mercados consumidores mais distantes preservando seu potencial nutricional, funcional e sensorial. Como alternativa, a secagem em camada de espuma é indicada para a produção de alimentos a partir polpas de frutas com o objetivo de disponibilizar ao consumidor produtos com o máximo de características nutricionais e funcionais preservadas. O produto desidratado oferece outras vantagens como maior período de conservação e facilidade para transporte (EMBRAPA, 2010).

A técnica de secagem, cujo intuito de remover a água livre do produto através da aplicação de calor, impede assim a deterioração, além de facilitar o transporte. Estudos apontam que a secagem em camada de espuma tem influência mínima sobre as propriedades, tanto físicoquímicas, quanto nutricionais das polpas de fruta, mantendo-as o com as características próximas a do estado in natura (EMBRAPA, 2010; SILVA, 2015).

Este método de secagem consiste na formação de uma espuma por meio da adição de agentes emulsificantes nas polpas de frutas, através da incorporação de ar por agitação, permitindo uma maior facilidade para remoção de umidade, reduzindo o tempo de processo. Os produtos em pó, provenientes de polpas de frutas estão sendo muito utilizados nas indústrias alimentícias, devido ao seu baixo custo de processamento em relação a sua conservação, transporte, armazenamento e embalagens (SILVA, 2008). 
A cinética de secagem é a velocidade na qual o alimento perde umidade, sendo influenciada pela composição do mesmo, umidade relativa e velocidade do ar e a temperatura aplicada para a realização do processo (SILVA, 2015).

Como a pitanga é uma fruta muito sensível, desta forma a sua durabilidade pós-colheita é muito baixa, sendo necessária a aplicação de algum tratamento para aumentar a sua vida útil, uma alternativa é a utilização de secagem em camada de espuma, a qual o produto final resulta em um pó com umidade baixa e características físico químicas e sensoriais muito próximas da fruta in natura (ALEXANDRE et al., 2014).

Portanto, o presente estudo objetivou a realização da cinética de secagem em camada de espuma e analisar as propriedades físico-químicas em diferentes temperaturas das polpas de pitanga in natura e secas.

\section{Material e Métodos}

As análises foram realizadas no Laboratórios da Universidade do Estado de Mato Grosso - Campus Deputado Estadual Renê Barbour. As pitangas foram coletada no munícipio de Barra do Bugres localizado no Estado de Mato Grosso - Brasil. O aditivo emulsificante Emustab® seleta (composto por monoglicerideos de ácidos graxos, monoestearato de sorbitana, polioxietileno de monoestearato de sorbitana e sorbato de potássio) foi adquirido no comércio local.

\section{Obtenção da espuma}

As frutas foram higienizadas, despolpadas e trituradas em liquidificador doméstico até a homogeneização completa. Em seguida, o emulsificante foi adicionado na concentração de $5 \%$ em relação à massa da polpa e a mistura agitada em batedeira doméstica em velocidade máxima por 8 minutos. A espuma resultante foi distribuída em placas de Petri (aproximadamente $10 \mathrm{~g}$ em cada placa), as quais foram acondicionadas em estufa com circulação forçada de ar para a realização da secagem.

\section{Secagem da polpa da pitanga}

As secagens das espumas das polpas de pitanga foram realizadas nas temperaturas de $60 \mathrm{C}$ e $70^{\circ} \mathrm{C}$, sendo finalizada ao atingir o equilíbrio (massa constante). Após a secagem, o produto foi retirado das placas de Petri com auxílio de uma espátula, acondicionados em embalagem de polietileno e armazenadas no congelador até realização das análises. 


\section{Modelagem matemática}

Para analisar o comportamento da perda de umidade ao decorrer da secagem foram utilizados os modelos semi-empíricos de Midilli e Kucuk (2002), Page (1949), Henderson e Pabis (1961) e para descrever o comportamento da secagem (Quadro 1). O modelo escolhido para representar a cinética de secagem da polpa de pitanga em camada de espuma, foi o que apresentou melhor ajuste, avaliado através do coeficiente de determinação $\left(\mathrm{R}^{2}\right)$, pelo erro médio padrão e pelo princípio da parcimônia.

Quadro 1. Modelos matemáticos utilizados para descrever a cinética de secagem
\begin{tabular}{|c|c|}
\hline Designação do Modelo & Modelos matemáticos \\
\hline Midilli e Kucuk & $\mathrm{RX}=\mathrm{a} \exp \left(-\mathrm{kt}^{\mathrm{n}}\right)+\mathrm{bt}$ \\
\hline Page & $\mathrm{RX}=\exp \left(-\mathrm{kt}^{\mathrm{n}}\right)$ \\
\hline Henderson e Pabis & $\mathrm{RX}=\mathrm{a} \exp (-\mathrm{kt})$ \\
\hline
\end{tabular}

Onde: RX corresponde a razão de umidade do produto, adimensional; t é o tempo de secagem, min; $\mathrm{k}$, constante de secagem, $\min ^{-1}$, e a, b, n são os coeficientes dos modelos.

\section{Análises fisico-químicas}

As amostras foram submetidas às análises de $\mathrm{pH}$, cinzas, vitamina $\mathrm{C}$, e acidez total titulável e umidade todas realizadas em triplicata, para maior confiabilidade nos resultados obtidos, seguindo a metodologia do Intituto Adolfo Lutz (2008).

\section{Análises de antocianinas totais e compostos fenólicos totais}

\section{Preparo dos extratos}

Amostras de pitanga in natura e após a secagem foram diluídas em solução de etanol $70 \%$ e submetidas à extração por agitação durante $24 \mathrm{~h}$. Em seguida, as amostras foram filtradas a vácuo e centrifugadas por 10 minutos. O sobrenadante foi armazenado em fracos âmbar em refrigeração em ausência de luz para análises físico-químicas.

\section{Antocianinas totais}

O conteúdo de antocianinas totais dos extratos foi quantificado pelo método de $\mathrm{pH}$ único (Lee e Francis, 1972). A determinação de antocianinas foi realizada diluindo alíquota dos extratos com solução etanol: $\mathrm{HCl} 1,5 \mathrm{~mol} \cdot \mathrm{L}^{-1}(85: 15, \mathrm{v} / \mathrm{v})$. Após a diluição, foi realizada medida da absorbância por espectrofotometria a $535 \mathrm{~nm}$. O teor de antocianinas foi calculado utilizando a equação: $A=\varepsilon_{1 \mathrm{~cm}}$. b. C'

Em que: $A$ = Absorbância (Abs) em $535 \mathrm{~nm} ; \varepsilon_{1 \mathrm{~cm}}=$ Coeficiente de absortividade (98,2 L.cm 
${ }^{1} \cdot \mathrm{g}^{-1}$ ) - considerando cianidina-3-glicosídeo (FULEKI e FRANCIS, 1968); C' = Concentração $\left(\mathrm{g} . \mathrm{L}^{-1}\right), \mathrm{b}=$ espessura da cubeta $(1 \mathrm{~cm})$. O conteúdo total de antocianinas foi expresso em $\mathrm{mg} / 100 \mathrm{~g}$ de polpa.

\section{Compostos fenólicos totais}

O teor de compostos fenólicos totais foi determinado de acordo com metodologia de Genovese et al., (2008).

Em tubos de ensaios foram pipetados $0,6 \mathrm{ml}$ do extrato obtido, $3 \mathrm{~mL}$ do reagente FolinCiocalteu e, após 3 minutos adicionados 2,4 mL da solução carbonato de sódio 7,5\% (p/v), e aguardar 1 hora em ausência de luz. Posteriormente foi realizada a leitura no espectrofotômetro a uma absorbância de $760 \mathrm{~nm}$. Foi utilizado como padrão de referência o ácido gálico. Os resultados foram expressos em mg equivalentes de ácido gálico por 100 gramas de amostra.

\section{Resultados e Discussão}

\section{Cinética de secagem}

Como a secagem foi realizada em camada de espuma, o procedimento apresentou rapidez devido à aeração existente na amostra. Na Figura 2 é possível observar as curvas de secagem em camada de espuma nas temperaturas de 60 e $70{ }^{\circ} \mathrm{C}$.

Figura 2. Curvas de secagem em camada de espuma, nas temperaturas de 60 e $70{ }^{\circ} \mathrm{C}$.

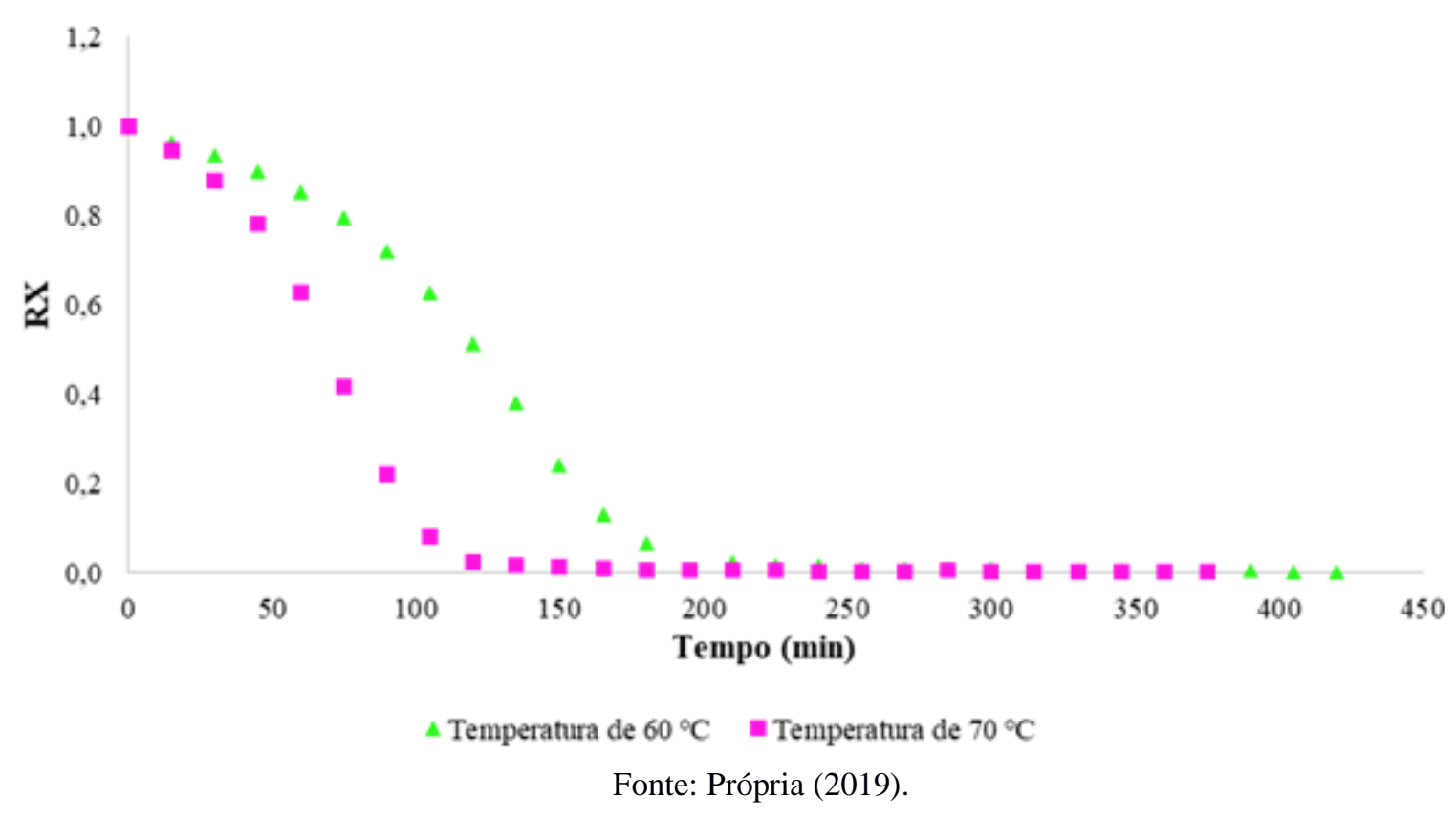


É notório que a amostra submetida à temperatura de $70{ }^{\circ} \mathrm{C}$ atingiu a umidade de equilíbrio com menor tempo quando comparada com a de $60{ }^{\circ} \mathrm{C}$, visto que, com a temperatura mais elevada a perda de água acontece com maior facilidade, desta forma adiantando o processo de secagem, esse fator também foi observado na secagem de acerola (ARAÚJO et al., (2017) e uvaia (RIGUETO et al., 2018). Conforme aumentou-se a temperatura, o tempo de secagem reduziu, ficando em torno de 230 e 150 minutos para as temperaturas de 60 e $70{ }^{\circ} \mathrm{C}$ respectivamente.

A medida na qual a temperatura aumenta a inclinação da curva também aumenta, pois com a temperatura elevada existe uma maior quantidade de calor transferido do ar para a amostra e consequentemente a migração de água do interior para a superfície da amostra ocorre com maior velocidade (REIS et al., 2012). Esse fator pode ser observado na Figura 2, visto que a curva de $70^{\circ} \mathrm{C}$ possui maior inclinação do que a de $60{ }^{\circ} \mathrm{C}$.

\section{Modelagem Matemática}

Na Tabela 1 é possível observar os parâmetros dos modelos matemáticos que foram utilizados para representar a cinética de secagem da pitanga a $60{ }^{\circ} \mathrm{C}$, sendo os modelos de Midilli e Kucuk e Page, apresentando coeficientes de determinação $\left(\mathrm{R}^{2}\right)$ de 0,985961 e 0,996584 respectivamente. É importante ressaltar que o modelo de Henderson e Pabis foi testado, mas os modelos escolhidos apresentaram maior coeficiente de determinação e menor erro.

Tabela 1. Parâmetros dos modelos matemáticos ajustados para a cinética de secagem em camada de espuma da pitanga a $60{ }^{\circ} \mathrm{C}$.

\begin{tabular}{cccc}
\hline Parâmetros & Midilli e Kucuk & Page & Henderson e Pabis \\
\hline $\mathrm{a}$ & 1,092654 & - & 1,316839 \\
$\mathrm{~b}$ & 0,000000 & - & - \\
$\mathrm{k}\left(\mathrm{min}^{-1}\right)$ & 0,000354 & 0,000014 & 0,011477 \\
$\mathrm{n}$ & 1,661881 & 2,289229 & - \\
$\mathrm{R}^{2}$ & 0,985961 & 0,996584 & 0,943303 \\
Erro & 1,338369 & 0,674172 & 2,672400 \\
\hline
\end{tabular}

Fonte: Própria (2019).

O modelo que melhor se ajustou a secagem a $60{ }^{\circ} \mathrm{C}$ foi o de Page, visto que apresentou menor erro $(0,674)$ e um maior coeficiente de determinação $\left(R^{2}=0,996584\right)$ (Tabela 1$)$. 
Entre os três modelos matemáticos apresentados na Tabela 2, o modelo de Page e Midilli e Kucuk foram os que se ajustaram adequadamente a cinética de secagem à $70{ }^{\circ} \mathrm{C}$, visto que apresentaram correlação de 0,993455 para Midilli e Kucuk e 0,996027 para Page, porém o modelo de Henderson e Pabis não se ajustou como o esperado, visto que o coeficiente de determinação $\left(\mathrm{R}^{2}\right)$ foi menor que os demais e o erro maior. $\mathrm{O}$ modelo que melhor se ajustou à cinética de secagem à $70{ }^{\circ} \mathrm{C}$ foi o de Page, o qual teve maior coeficiente de determinação e menor erro.

Tabela 2. Parâmetros dos modelos matemáticos ajustados para a cinética de secagem em camada de espuma da

\begin{tabular}{cccc}
\multicolumn{4}{c}{ pitanga a $70^{\circ} \mathrm{C}}$. \\
\hline Parâmetros & Midilli e Kucuk & Page & Henderson e Pabis \\
\hline $\mathrm{a}$ & 1,002477 & - & 1,268298 \\
$\mathrm{~b}$ & 0,000004 & - & - \\
$\mathrm{k}\left(\mathrm{min}^{-1}\right)$ & 0,000425 & 0,000169 & 0,019490 \\
$\mathrm{n}$ & 1,810642 & 2,003234 & - \\
$\mathrm{R}^{2}$ & 0,993455 & 0,996027 & 0,953642 \\
Erro & 0,589005 & 0,461205 & 1,522815
\end{tabular}

Fonte: Própria (2019).

Através da Figura 3 é possível observar o ajuste dos modelos Midilli e Kucuk e Page aos dados experimentais, obtidos através da cinética de secagem em camada de espuma da polpa de pitanga.

Figura 3. Ajuste dos modelos de Midilli e Kucuk e Page para secagem em camada de espuma da polpa de pitanga a $60{ }^{\circ} \mathrm{C}$.



Fonte: Própria (2019). 
Na Figura 4 estão apresentados os ajustes dos modelos matemáticos Midilli Kucuk, na secagem da polpa de pitanga a $70{ }^{\circ} \mathrm{C}$

Figura 4. Ajuste dos modelos de Midilli e Kucuk e Page para secagem em camada de espuma da polpa de pitanga a $70{ }^{\circ} \mathrm{C}$

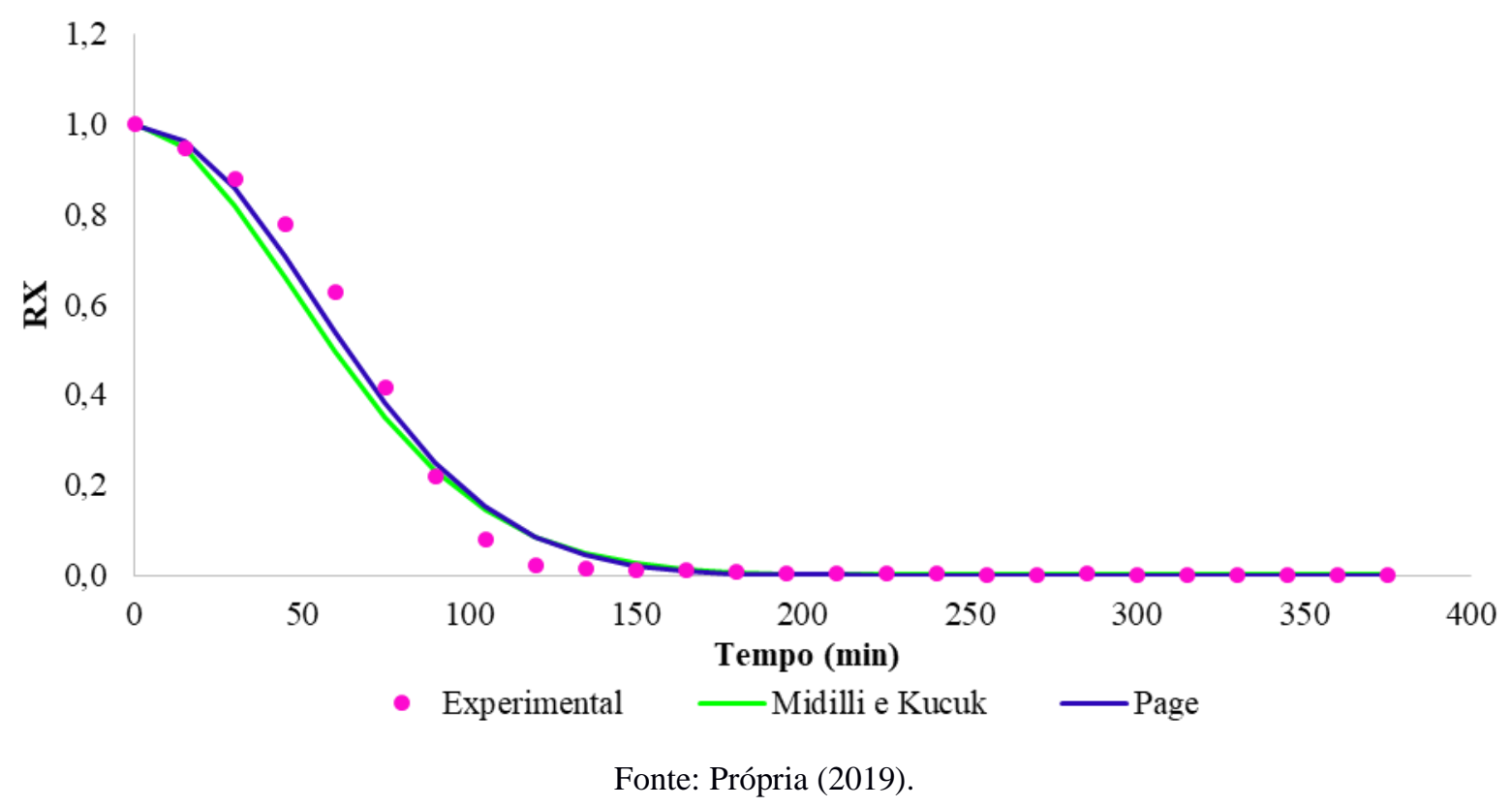

O modelo semi-empírico de Page apresentou excelente ajuste em cinética de secagem em camada de espuma à temperatura de $70{ }^{\circ} \mathrm{C}$ realizada com acerola (ARAÚJO et al., 2017), manga (GUIMARÃES et al., 2017), uvaia (RIGUETO et al., 2018), tamarindo (SILVA et al., 2008), cenoura (DELMIRO, 2016) e mandacaru (MELO et al., 2013), com correlações de 0,997; 0,998; 0,996 0,998; 0,994 e 0,998 respectivamente. O modelo Page também se ajustou adequadamente à secagens em camada de espuma realizadas à $60^{\circ} \mathrm{C}$ em manga (GUIMARÃES et al., 2017), uvaia (RIGUETO et al., 2018), tamarindo (SILVA et al., 2008) e acerola (ARAÚJO et al., 2017), obtendo coeficiente de determinação de 0,999; 0,994; 0,997 e 0,997.

Rigueto et al. (2018) realizou a cinética de secagem em camada de espuma de uvaia em diferentes temperaturas, o modelo semi-empírico de Midilli e Kucuk apresentou ótimo ajuste nas curvas geradas com as temperaturas de 70 e $60{ }^{\circ} \mathrm{C}$, obtendo coeficiente de correlação de 0,989 e 0,993 respectivamente. No estudo realizado por Silva (2008) esse modelo também se ajustou excelentemente na cinética de secagem em camada de espuma de tamarindo nas temperaturas de 60 e $70{ }^{\circ} \mathrm{C}$, onde os ambos coeficientes de correlação foram equivalentes a 0,998 . 


\section{Análises fisico-químicas da pitanga}

Os resultados da caracterização físico-química da polpa in natura e do pó obtido através da formação de uma espuma com adição de $5 \%$ de emulsificante e submetida a secagem a 60 e $70{ }^{\circ} \mathrm{C}$ estão apresentados na Tabela 3.

Tabela 3. Caracterização físico-química da polpa de pitanga in natura e após a secagem em camada de espuma.

\begin{tabular}{l|c|c|c}
\hline \multicolumn{1}{c}{ Parâmetros } & \multicolumn{1}{c}{ In natura } & Polpa seca a 60 \\
& & \\
\hline $\mathrm{pH}$ & $3,12 \pm 0,05^{\mathrm{a}}$ & $3,12 \pm 0,01^{\mathrm{a}}$ & Polpa seca a 70 $^{\circ} \mathbf{C}$ \\
\hline Cinzas (\%) & $0,27 \pm 0,003^{\mathrm{a}}$ & $2,11 \pm 0,05^{\mathrm{b}}$ & $2,16 \pm 0,02^{\mathrm{b}}$ \\
\hline Vitamina C (mg/100g) & $33,78 \pm 0,79^{\mathrm{a}}$ & $74,37 \pm 2,13^{\mathrm{b}}$ & $59,27 \pm 1,0^{\mathrm{c}}$ \\
\hline Acidez Total Titúlavel (g/100g) & $3,01 \pm 0,02^{\mathrm{a}}$ & $15,88 \pm 0,16^{\mathrm{b}}$ & $15,7 \pm 0,012^{\mathrm{b}}$ \\
\hline Umidade (\%) & $90,52 \pm 0,021^{\mathrm{a}}$ & $16,27 \pm 0,94^{\mathrm{b}}$ & $13,46 \pm 0,16^{\mathrm{c}}$ \\
\hline Antocianinas (mg/100g de polpa) & $1,01 \pm 0,001^{\mathrm{a}}$ & $6,24 \pm 0,012^{\mathrm{b}}$ & $4,46 \pm 0,02^{\mathrm{c}}$ \\
\hline Compostos Fenólicos (mg de & $114,09 \pm 0,11^{\mathrm{a}}$ & $660,27 \pm 0,04^{\mathrm{b}}$ & $684,9 \pm 0,21^{\mathrm{b}}$ \\
ácido gálico/100g de polpa) & & & \\
\hline
\end{tabular}

Fonte: Própria (2019).

Os resultados foram expressos como média \pm desvio padrão. Média nas colunas seguidas por letras diferentes na mesma linha são estatisticamente diferentes $(p<0,05)$.

Os resultados encontrados na caracterização físico-química da polpa de pitanga in natura estão de acordo com a literatura, dado que, Vergara et al., (2016) encontraram pH de 3,35 e teor de cinzas equivalente a 0,26\%. Além disso, Batista et al., (2014) obtiveram 90,6\% de teor de umidade e Rodrigues et al., (2016) encontraram 25,06 mg de vitamina C/100g de polpa, valores próximos dos apresentados na Tabela 3.

Alexandre et al., (2014) realizaram a cinética de secagem em camada de espuma de pitanga à $70{ }^{\circ} \mathrm{C}$. Para a formação da espuma foi adicionado $7,5 \%$ de do emulsificante e estabilizante Emustab ${ }^{\circledR}$ e 4,5\% do espessante comercial Super Liga Neutra ${ }^{\circledR}$. Na caracterização físico-química do pó oriundo da secagem foi obtido teor de umidade de 20,40\% e pH de 2,8, valores relativamente próximos aos apresentados na Tabela 3 para pó de pitanga seco a $70{ }^{\circ} \mathrm{C}$, sendo $13,46 \%$ e 3,13 , respectivamente. Existe uma pequena diferença entre os valores, fator que pode estar relacionado com a composição da espuma, pois no presente trabalho utilizou-se apenas 5\% do emulsificante/estabilizante Emustab®.

Conforme a Normativa número 01 de 07 de janeiro de 2000 do Ministério da Agricultura, Pecuária e Abastecimento, a polpa de pitanga deve apresentar acidez mínima de $0,92 \mathrm{~g}$ de ácido/100g de polpa. Por conseguinte, o resultado referente a acidez total titulável da 
polpa de pitanga in natura (3,01 g de ácido/100g de amostra) exposto na Tabela 3 encontra-se dentro dos padrões estabelecidos pelo MAPA (BRASIL, 2000).

Batista et al., (2014) encontrou acidez total titulável em pitangas da região da Bahia equivalente à $1,86 \mathrm{~g}$ de ácido/100g de fruta, valor inferior ao determinado do presente estudo (Tabela 3). Entretanto, a acidez total titulável pode variar conforme o grau de maturação da fruta, visto que frutas no estádio de maturação mais avançado apresentam menor acidez; além disso, o solo no qual foi cultivada e o clima podem influenciar nas características físicoquímicas e nutricionais, justificando a diferença, visto que, as frutas foram cultivadas em diferentes estados (ALEXANDRE, 2014; HAMACEK, 2012.).

Como esperado, o teor de umidade reduziu bruscamente após a secagem, pois esse processo visa a remoção de água livre do alimento. Conforme a temperatura é elevada o teor de umidade reduz, dado que o teor de umidade do pó seco a $60^{\circ} \mathrm{C}(16,27 \%)$ é maior que a do pó seco à $70{ }^{\circ} \mathrm{C}(13,46 \%)$ e ambos apresentam teores inferiores à polpa in natura $(90,52 \%)$. Contudo a secagem do presente estudo foi realizada em manto de camada de espuma, ou seja, após a desidratação da polpa pitanga, o produto obtido foi uma farinha. Neste contexto comparou-se os resultados obtidos no presente com a legislação estabelecida a produtos desidratados em forma de farinhas de origem vegetal, teor de $15 \%(\mathrm{~m} / \mathrm{m})$, constatando assim que o índice de umidade encontrado neste trabalho na temperatura de $70^{\circ} \mathrm{C}$ está de acordo com o preconizado pela Agência Nacional de Vigilancia Sanitária.

Fatores como o tipo da fruta, estádio de maturação e condições climáticas estão diretamente relacionados com a quantidade de antocianinas e compostos fenólicos quantificados, justificando a diferença do teor de antocianinas $(1,01 \mathrm{mg} / 100 \mathrm{~g}$ de fruto) e compostos fenólicos (114,09 mg de ácido gálico/100g de polpa) da polpa in natura encontrados no presente estudo comparados aos de Vergara et al., (2016), o qual obteve 86,15 mg de ácido gálico/100 g de fruto de compostos fenólicos e 3,91 mg/100g de fruto de antocianinas, como as amostras de Vergara et al., (2016) foram coletadas no município de Pelotas no Rio Grande do Sul, é esperada essa oscilação devido aos diferentes climas, solos e talvez grau de maturação (ALMEIDA et al., 2011; CHIRINOS et al., 2010; EMBRAPA, 2010; ZANATTA et al., 2005).

A polpa in natura apresentou teor de compostos fenólicos inferior a polpa seca à temperatura de $60{ }^{\circ} \mathrm{C}$ e $70{ }^{\circ} \mathrm{C}$, sendo $114,09 \mathrm{mg}$ de ácido gálico/100g de polpa (in natura), 660,27 mg de ácido gálico/100g de polpa (polpa seca à $60^{\circ} \mathrm{C}$ ) e $684,9 \mathrm{mg}$ de ácido gálico/100g de polpa (polpa seca à $70^{\circ} \mathrm{C}$ ) (Tabela 3). O mesmo aconteceu para antocianinas, onde a polpa in natura obteve $1,01 \mathrm{mg} / 100 \mathrm{~g}$ de polpa, polpa seca à $60{ }^{\circ} \mathrm{C} 6,24 \mathrm{mg} / 100 \mathrm{~g}$ de fruto e polpa seca à $70{ }^{\circ} \mathrm{C} 4,46 \mathrm{mg} / 100 \mathrm{~g}$ de polpa. Isso acontece pois quando a polpa é transformada em 
espuma e submetida ao processo de secagem, seus componentes são concentrados devido a remoção de água livre, como a secagem em camada de espuma é um processo relativamente rápido, apresenta influência mínima sobre as propriedades, tanto físico-químicas, quanto nutricionais das polpas de fruta (EMBRAPA, 2010).

Esse fato justifica também o teor de vitamina $\mathrm{C}$ e cinzas, sendo que o pó resultante da secagem à 60 e $70{ }^{\circ} \mathrm{C}$ apresentou valores significativamente maiores comparados a polpa in natura (Tabela 3). Além disso, o emulsificante adicionado para obtenção da espuma possui natureza lipídica, consequentemente elevando o teor de cinzas da amostra seca (SANTOS, 2014).

\section{Conclusões}

A secagem em camada de espuma é uma alternativa de conservação de polpa de frutas, dado que, com a redução da água livre do alimento sua vida útil aumenta consideravelmente, além disso, o produto final apresenta boas características nutricionais, pois através da secagem existe a concentração dos componentes das frutas, vitamina $\mathrm{C}$ por exemplo.

Com o aumento da temperatura de 60 para $70{ }^{\circ} \mathrm{C}$, o tempo de secagem diminuiu, conforme esperado, visto que houve uma maior transferência de calor. Os modelos utilizados neste estudo (Page e Midilli e Kucuk) se ajustaram satisfatoriamente a cinética de secagem em camada de espuma da polpa de pitanga nas condições estudadas.

Deste modo, com os resultados apresentados fica evidente que o método de secagem em camada de espuma é uma alternativa eficiente para produzir e comercializar a polpa de pitanga e outras frutas de característica sazonal, além de abrir a possibilidade para a produção de novos produtos da farinha de polpa de pitanga. Contudo são necessários estudos mais amplos que comprovem a validade do método para outras frutas, contribuindo assim para a expansão da cadeia de suprimentos da indústria alimentícia.

\section{Referências}

ALEXANDRE, V. H.; de FIGUEIRÊDO, R. M. F.; QUEIROZ, A. J. DE M.; de OLIVEIRA, E. N. A. Armazenamento de pitanga em pó. Campina Verde - PB, 2014. Andrade, P. F. de S. Fruticultura. Paraná, 2016.

ALMEIDA, M.M.B. et al. Bioactive compounds and antioxidant activity of fresh exotic fruits from northeastern Brazil. Food Research International, v.44, p.2155-2159, 2011.

ANVISA. BRASIL. Agência Nacional de Vigilância Sanitária. Consulta Pública nº 80. Diário

Oficial da União - Brasília, DF, Brasil, 2019. 
ARAÚJO, C. DA S.; MACEDO L. L.; VIMERCATI, W. C.; SARAIVA, S. H.; OLIVEIRA, A. DO N.; TEIXEIRA, L. J. Q. Cinética de secagem de acerola em leito de espuma e ajuste de modelos matemáticos. Brazilian Journal of Food Technology, v. 20. 2017

BATISTA, A.D.; FONSECA, A.A.O.; COSTA, M.A.P.C.; BITTENCOURT, N.S. Caracterização física, físico-química e química de frutos de pitangueiras oriundas de cinco municípios baianos. Magistra, v.26, n.3, p.393-402, 2014.

BOURSCHEID, K.; VIEIRA, N. K.; LISBÔA, G. N.; KINUPP, V. F.; de BARROS I. B. I. Espécies Nativas da Flora Brasileira de Valor Econômico Atual ou Potencial: Eugenia uniflora Pitangueira. Brasília, 2011.

Brasil, Ministério da Agricultura, pecuária e Abastecimento - MAPA. 2000. Instrução Normativa $\mathrm{n}^{\circ}$ 01, de 7 de Janeiro de 2000. Regulamento da Lei ${ }^{\circ}$ 8.918, de 14 julho de 1994 , aprovado pelo Decreto $\mathrm{n}^{\mathrm{o}} 2.314$, de 4 de setembro de 1997, que dispõe sobre o regulamento técnico geral para fixação dos padrões de identidade e qualidade para polpa de fruta. Diário Oficial [da] República Federativa do Brasil. Brasília, DFCAMPOS, E. M.; SARTORELLI, P.A.R. Guia de árvores com valor econômico. São Paulo: Agroicone, 2015.

CHIRINOS, R.; GLARZA J.; BETALLELUZ-PALLARDEL, I.; PEDRESCHI, R.; CAMPOS D. Antioxidant compounds and antioxidant capacity of Peruvian camu camu Myrciaria dubia (H.B.K.) McVaugh) fruit at different maturity stages. Food Chemistry, London, v. 120, p. 1019-1024, 2010.

DANTAS, S.C.M. Desidratação de polpas de frutas pelo método foam-mat. Natal. 2010.

DELMIRO, T. M. Secagem da cenoura (daucus carota 1.) pelo método foam-mat. UNIVERSIDADE FEDERAL DO RIO GRANDE DO NORTE. Natal, 2016.

EMBRAPA. Princípios de Secagem de Alimentos. Planaltina-DF, 2010.

EMBRAPA. Valor nutricional da pitanga. Colombo - Pr. 2015.

GENOVESE, M.L.; PINTO, M.S.; GONÇALVES, A.E.S; LAJOLO, F.M. Bioactive compounds ande antioxdant capacity of exotic fruits and commercial frozen pulps from Brazil. Food Science ande Technology International, p. 2017-214, 2008.

GUIMARÃES, M. K. A.; FIGUEIRÊDO, R. M. F.; QUEIROZ, A. J. de M. Cinética de secagem em camada de espuma da polpa de manga cv. Keitt. Rev. Caatinga. v. 30, n. 1, p. 172 $-180,2017$.

HAMACEK, F. R.; Caracterização física, química e valor nutricional de espécies frutíferas do cerrado de Minas Gerais. Dissertação (Mestrado em Ciência da Nutrição). Universidade Federal de Viçosa, Viçosa, 2012.

HENDERSON, S. M.; PABIS, S. Grain drying theory I. Temperature effect on drying coefficient. Journal of Agricultural Engineering Research, v. 6, n. 3, p. 169-174, 1961.

INSTITUTO ADOLFO LUTZ. Métodos físico-químicos para análise de alimentos. 4 ed. São Paulo: Instituto Adolfo Lutz. 2008. 
LEE, D. H.; FRANCIS, F. J. Standardization of Pigment Analyses in Cranberries. HortScience, Stanford, v. 7, n. 1, p. 83-84, 1972.

LIMA, A. B. M.; DANTAS, S. C. de M.; JÚNIOR, S. M. de P.; DANTAS, T. N. P.; de MEDEIROS M. F. D. Influência dos adjuvantes na secagem da polpa de pitanga em leito de jorro. São Paulo, 2017.

MAPA - Ministério da Agricultura, Pecuária e Abastecimento. Plano nacional de desenvolvimento da fruticultura. 2016.

MELO, K. S.; FIGUEIRÊDO, R. M. F.; QUEIROZ, A. J. M.; FERNANDES, T. K. S.; BEZERRA, M. C. T. Secagem em camada de espuma da polpa do fruto do mandacaru: experimentação e ajustes de modelos matemáticos. Revista Caatinga, Mossoró, v. 26, n. 2, p. 10-17, 2013.

MIDILLI, A.; KUCUK, H.; YAPAZ, Z. A new model for single-layer drying. Drying Technology, New York, v.20, n.7, p.1503-1513, 2002.

PAGE, G. E. Factors influencing the maximum of air-drying shelled corn in thin layer. Thesis Dissertation (M.Sc.) - Purdue University, Indiana, 1949.

REIS, R C.; CORRÊA, P. C.; DEVILlA, I. A.; SANTOS, E. S.; ASCHERI, D. P. R.; SERVULO, A. C. O.; SOUZA, A. B. M. 2013. Drying of yam starch (Discorea ssp.) and glycerol filmogenic solutions at different temperatures. LWT - Food Science and Technology, v. 50, n. 2, p. 651-656. 2012.

RIGUETO, C. V. T.; EVARISTO, L. M.; GERALDI, C. A. Q.; COVRE, L. Influência da temperatura de secagem de uvaia (Eugenia pyriformis) em camada de espuma. Engevista, v. 20, n.4, p.537-547, 2018.

RODRIGUES, L. V.; MARQUES-BUNGART, G. A.; TOBAL T. M. Geleia de pitanga: caracterização bioativa, nutricional e sensorial. In: Congresso Brasileiro de Ciência E Tecnologia de Alimentos, Gramado. Anais. Gramado: FAURGS, 2016.

SANTOS, C. A.; LIRENY, C. C. M.; GONÇALVES, A. G. Emulsificantes: atuação como modifi cadores do processo de cristalização de gorduras. Ciência Rural, Santa Maria, v.44, n.3, p.567-574, 2014.

SILVA, A. S.; GURJÃO, K. C. DE O.; ALMEIDA, F. DE A. C.; BRUNO, R. DE L. A.; PEREIRA, W. E. Desidratação da polpa de tamarindo pelo método de camada de espuma. Ciência e Agrotecnologia, Lavras, v. 32, n.6, p. 1899-1905, 2008

SILVA, E.S; OLIVEIRA, J; MACHADO, A.V; COSTA, R.O. Secagem de Grãos e Frutas: Revisão Bibliográfica. Revista Brasileira de Agrotecnologia (Garanhuns - PE - Brasil) v.5,n.1,p. 19-23, 2015.

SILVA, S. DE M. Pitanga. Revista brasileira de fruticultura. v. 28, n. 1, p. 1 - 159. Areia PB. 2016. 
VERGARA, L.P.; SOUZA, V.R.D.; CHIM, J.F.; RODRIGUES, R.S.; FRANZON, R.C. Compostos bioativos em polpa de pitanga vermelha. In: Congresso Brasileiro de Ciência $\mathrm{E}$ Tecnologia de Alimentos, Gramado. Anais. Gramado: FAURGS, 2016.

VOLPATO, C.; LONGHI, A.; SPERB, M. Frutas nativas: alimentos locais, sabores e ingredientes especiais. Passo Fundo - RS. 2015.

ZANATTA, C.F; CUEVAS, E., BOBBIO, F.O; WINTERHALTER P.; MERCADANTE, A.Z. Determination of anthocyanins from camucamu (Myrciaria dubia) by HPLC-PDA, HPLC-MS, and NMR. Journal of Agricultural and Food Chemistry, v.53, p.9531- 9535, 2005. 